\title{
Arizona Cancer Center
}

National Cancer Institute

\section{Source}

National Cancer Institute. Arizona Cancer Center. NCI Thesaurus. Code C39366.

The Arizona Cancer Center runs a scientific program in cancer prevention and control with special emphasis on colon, breast, prostate, and skin cancer. It was founded as a division of the University of Arizona's College of Medicine in 1976, became an NCldesignated cancer center in 1978, and received Comprehensive Cancer Center status in 1990. 